\title{
Methodology Review: Using Dual-Energy X-Ray Absorptiometry (DXA) for the Assessment of Body Composition in Athletes and Active People
}

\begin{abstract}
Alisa Nana, Gary J. Slater, Arthur D. Stewart, and Louise M. Burke
Dual energy X-ray absorptiometry (DXA) is rapidly becoming more accessible and popular as a technique to monitor body composition, especially in athletic populations. Although studies in sedentary populations have investigated the validity of DXA assessment of body composition, few studies have examined the issues of reliability in athletic populations and most studies which involve DXA measurements of body composition provide little information on their scanning protocols. This review presents a summary of the sources of error and variability in the measurement of body composition by DXA, and develops a theoretical model of best practice to standardize the conduct and analysis of a DXA scan. Components of this protocol include standardization of subject presentation (subjects rested, overnight-fasted and in minimal clothing) and positioning on the scanning bed (centrally aligned in a standard position using custom-made positioning aids) as well as manipulation of the automatic segmentation of regional areas of the scan results. Body composition assessment implemented with such protocol ensures a high level of precision, while still being practical in an athletic setting. This ensures that any small changes in body composition are confidently detected and correctly interpreted. The reporting requirements for studies involving DXA scans of body composition include details of the DXA machine and software, subject presentation and positioning protocols, and analysis protocols.
\end{abstract}

Keywords: DEXA, physique, monitoring

Although surface anthropometry protocols are still the primary source of information on body composition in athletes, the increasing availability and popularity of new techniques for physique assessment have enabled them to be considered by sports scientists as additional tools for use in the everyday monitoring of athletes. In particular, increased access to dual-energy X-ray absorptiometry (DXA) technology, through sports institutes or commercial radiology clinics, has generated interest in its potential to provide timely, detailed information on body composition for total body as well as regional body areas (right and left sides, arms, legs and trunk).

DXA provides information on three compartments of body composition, according to the terminology "fat mass," "lean mass" or the "fat-free soft tissue" and "bone mineral content." Although there is some disagreement on the definition of these terms and what is actually mea-

Nana and Burke are with the Dept. of Sports Nutrition, Australian Institute of Sport, Canberra, Australia. Slater is with the University of the Sunshine Coast, Maroochydore, Australia. Stewart is with the Institute of Health and Welfare Research, Robert Gordon University, Aberdeen, UK. Address author correspondence to Alisa Nana at alisa.nana@ausport.gov.au. sured according to other techniques of body composition assessment, this review will use the DXA-analysis terminology for describing body composition compartments. A cursory summary of the advantages and disadvantages of the use of DXA for physique assessment of athletes is provided in Table 1 . The limitations of DXA, previously identified in its use for monitoring body composition in the general population, merit specific exploration in relation to athletes, given their potentially unique physique traits, including extreme ranges in stature, lean mass and body fat.

\section{Specific Validity and Reliability of DXA in Athletic Populations}

The interpretation of body composition measurements via DXA, as is the case for any measurement of physique, requires an appreciation of concepts that are commonly referred to as validity and reliability. Validity refers to the agreement between the value of a measurement and its true value (Hopkins, 2000) or, more broadly, how well a measure is representative of another. Validity is important for the precision of a single measurement, and one of the consequences of poor measurement validity is the reduction in ability to characterize relationships between vari- 
Table 1 Advantages and Disadvantages of DXA for Physique Assessment of Athletes

\begin{tabular}{ll}
\hline Advantages & Disadvantages \\
\hline - Suitable for most athletes & $\bullet$ Expensive equipment \\
- Fast $(\sim 5$ min for fanbeam up to $\sim 15$ for some pencil beam $)$ & $\bullet$ Not portable \\
- Able to provide regional body composition & $\begin{array}{l}\text { S Scanning bed is smaller than typical physique of many larger } \\
\text { athletes }\end{array}$ \\
$\begin{array}{ll}\text { - Low radiation dose }(\sim 0.5 \mu \mathrm{Sv}) \text { and safe for sequential mea- } \\
\text { surements }\end{array}$ & $\bullet$ Trained technician required \\
- Nonintrusive & $\begin{array}{l}\text { - Manufacturers' body composition estimation algorithms are } \\
\text { not developed on athletes }\end{array}$ \\
& $\bullet$ Unable to directly compare results between different DXA \\
& machines (need specific regression equations) \\
\hline
\end{tabular}

ables in descriptive studies (Hopkins, 2000). Although there are studies of the validity of DXA estimates of body composition in general or obese populations, even the best investigations are limited to comparisons with measurements derived from several other indirect techniques within a multicompartment model, rather than the gold standard of chemical measurements of cadavers. Even fewer of these indirect studies of the validity of DXA technology in physique assessment exist in athletic populations (Arngrimsson et al., 2000; Moon et al., 2009; Santos et al., 2010; Silva et al., 2006; Withers et al., 1998). For further discussions of the validity of DXA estimates of body composition, the reader is referred to separate review papers (Ackland et al., 2012; T. G. Lohman et al., 2000; Toombs et al., 2011).

Reliability refers to the reproducibility of the observed value when the measurement is repeated (Hopkins, 2000). Reliability results from high precision of a single measurement, and also facilitates the researcher's or clinician's ability to detect changes between serial measurements on the same athlete. This is an important consideration if DXA is to be used to assess body composition throughout the athlete's maturation or training history or as a result of a specific intervention. It is only recently that issues of reliability have been systematically examined in athletic populations; the results of such studies are important in informing optimal practice in the future as well as highlighting apparent or potential deficiencies in the current literature.

Accordingly, the aims of this review were 1) to discuss the current use of DXA measurements of body composition among active or athlete populations in research or practice to assess the apparent importance given to the reliability of measurements and the standardization of scanning protocols, 2) to explore the reliability of DXA in assessing body composition, with investigation of potential sources of biological and technical variations, and 3) to develop practical strategies to minimize these errors which can be integrated into a standardized Best Practice DXA Scanning Protocol for implementation in an athletic setting in both research and servicing applications.

\section{How Well Are Standardization Procedures Being Incorporated Into Current Uses of DXA Estimates of Body Composition of Athletes?}

There are several ways that DXA estimates of body composition of athletes are currently being used in a research context (Table 2). Examples include its use to describe physique traits across sports or within subgroups of athletes within the same sport (Harley et al., 2011; Smathers et al., 2009; Sutton et al., 2009a; Warrington et al., 2009; Wittich et al., 2001). It has also been used to monitor acute changes in body composition (muscle glycogen, protein, and adipose tissue) over an ultra-endurance event (Mueller et al., 2013). DXA has been used as a reference method from which other physique assessment tools are validated (Duz et al., 2009; LaForgia et al., 2009; Moon et al., 2009; Wang et al., 1998) as well as a means of measuring body composition to assess an athlete's suitability for a weight class in a weight division sport (Clark et al., 2007). In the near future, we anticipate that the increased availability of DXA will facilitate a broader use across both research and field settings. In particular, the monitoring of physique changes as an outcome of interventions (Cribb \& Hayes, 2006) or longitudinal tracking of physique traits over a period of time is of high interest within sports (Harley et al., 2011). Across all these settings, there would be added value in implementing a DXA protocol with high reliability.

Accordingly, we reviewed recent publications involving DXA measurements of body composition in active or athletic populations to identify how the standardization of scanning protocols was undertaken and reported (Table 2). Specifically, a literature search using PubMed (www.ncbi.nlm.nih.gov/pubmed/) for publications of interest from 1997 to 2013 was performed. The following keywords were used: DXA, DEXA, dualenergy X-ray absorptiometry, body composition, athlete, and sport. The inclusion criteria were publications that used DXA to provide measurements of body composition in the athletic or active populations at various competitive 
levels, regardless of age, physique, sports, or disability. The methods sections of these studies were scrutinized for details about protocols used to undertake whole-body DXA scans, with specific interest in standardization procedures that were implemented in terms of subject presentation and machine or technician issues, as well as information on the reliability of these techniques (expressed as coefficient of variation or CV).

In general, information on the specific procedures incorporated into scanning protocols was sparse. For example, in terms of subject presentation, only a third of studies required subjects to be in a fasted state, a further third allowed subjects to eat lightly or drink fluids before the scan, and the remaining studies did not provide details of this aspect of their DXA assessment protocol, despite literature documenting acute food and fluid intake impacting reliability of measurement (Going et al., 1993; Horber et al., 1992; Thomsen et al., 1998; Vilaca et al., 2009). About $70 \%$ of reviewed studies failed to report any detail on subject positioning on the scanning bed and while most studies provided details of the type and model of DXA scanner used, $\sim 30 \%$ failed to report the software version used during analysis, despite the fact that these factors are known to influence reliability of measurement (Kistorp \& Svendsen, 1998; Lambrinoudaki et al., 1998; M. Lohman et al., 2009; Van Loan et al., 1995). Approximately 50\% of studies reported the error of measurement as a coefficient of variation $(\mathrm{CV})$, ranging from $0.5-2.5 \%$ for lean mass and $0.8-5.0 \%$ for fat mass. However, it was unclear how this was calculated: with phantom scanning or subjects with repositioning in between scans. Many investigations referenced the CV calculated by DXA machines located at other centers or of other studies.

The use of DXA in the daily athlete servicing setting should also be considered. According to responses from a survey by the Working Group of the International Olympic Committee on body composition assessment, ?40\% of sports professionals have used DXA as one of the methods to measure body composition in their athletic practices (Meyer et al., 2013). The authors noted that DXA was more often used with athletes who were of international level and in weight-sensitive sports. Unfortunately, this survey did not provide any information on the protocols practitioners used to undertake DXA measurements of body composition in athletic populations (Meyer et al., 2013).

\section{Understanding the Reliability of DXA Measurements of Body Composition in Athletic Populations}

The processes of undertaking a DXA scan to measure body composition are illustrated in Figure 1, and incorporate sources of variability or error that can be divided into two types: technical (machine and technician) and biological (day-to-day) variations. Variables contributing to these errors include those that can be controlled and others that must remain residual.

\section{Technical Variation}

Technical errors can include machine inherent errors ("noise" that cannot be altered or within-machine error), or those introduced by the lack of standardization of subject preparation (choice of clothing, wearing of jewelry and other metal objects), subject positioning, where differences in placement of limbs on the scanning bed causes variations in body composition (Margulies et al., 2005), and the technician's protocols in demarcating regional (arms, legs and trunk) estimates of body composition (De Lorenzo et al., 1997; Madsen et al., 1997; Margulies et al., 2005; Mazess et al., 1990).

Subject Positioning The impact of subject positioning on body composition estimates was first confirmed in a group of healthy subjects who underwent two sequential DXA scans (Hologic QDR 2000 fan-beam): the first undertaken in a supine position and the second in a prone position (Lambrinoudaki et al., 1998). Wholebody estimates of fat and lean mass differed by $\sim 5 \%$ and $\sim 3 \%$, respectively. Regional estimates of fat mass were nonsignificant for arms, while trunk lean mass was different between supine and prone positions. In a similar study, 30 male volunteers underwent three DXA scans (a narrow fan-beam Lunar Prodigy) in the following positioning order: supine, prone, and supine (M. Lohman et al., 2009). Strong correlations in total fat mass and lean mass measurements were found between supine versus prone position $(r=.95-0.99)$. However, upper and lower limb estimates between positions were weaker $(r=.72$ for upper limb lean mass). Differences in estimates of body composition between supine and prone positions, at least for fan-beam scanners, were thought to be due to a combination of factors such as beam hardening effect (the preferential loss of lower energy photons relative to high-energy photons as a result of increasing body thickness) (Kohrt, 1995; Prior et al., 1997) as a result of alteration of tissue depth and attenuation ratios, as well as magnification error due to geometric distortion of fan-beam scanners (Lambrinoudaki et al., 1998; M. Lohman et al., 2009). Other, even smaller, variations in subject positioning such as the external rotation of the leg, affects the partial volume of pixels containing bone and soft tissue. The differences in estimates of body composition are then amplified due to the underpinning assumption associated with soft tissue estimation by DXA (Andreoli et al., 2009; Laskey, 1996; Nord \& Payne, 1995; Pietrobelli et al., 1996).

Analysis Mode for Regional Composition Most DXA software automatically defines areas of regional body estimates (i.e., estimates of left and right arms, legs and trunk). However, the technician can choose to manually demarcate segmental lines on the scans, and in some machines, manual demarcation is compulsory. It is unclear whether automatic-, semiautomatic or manually 


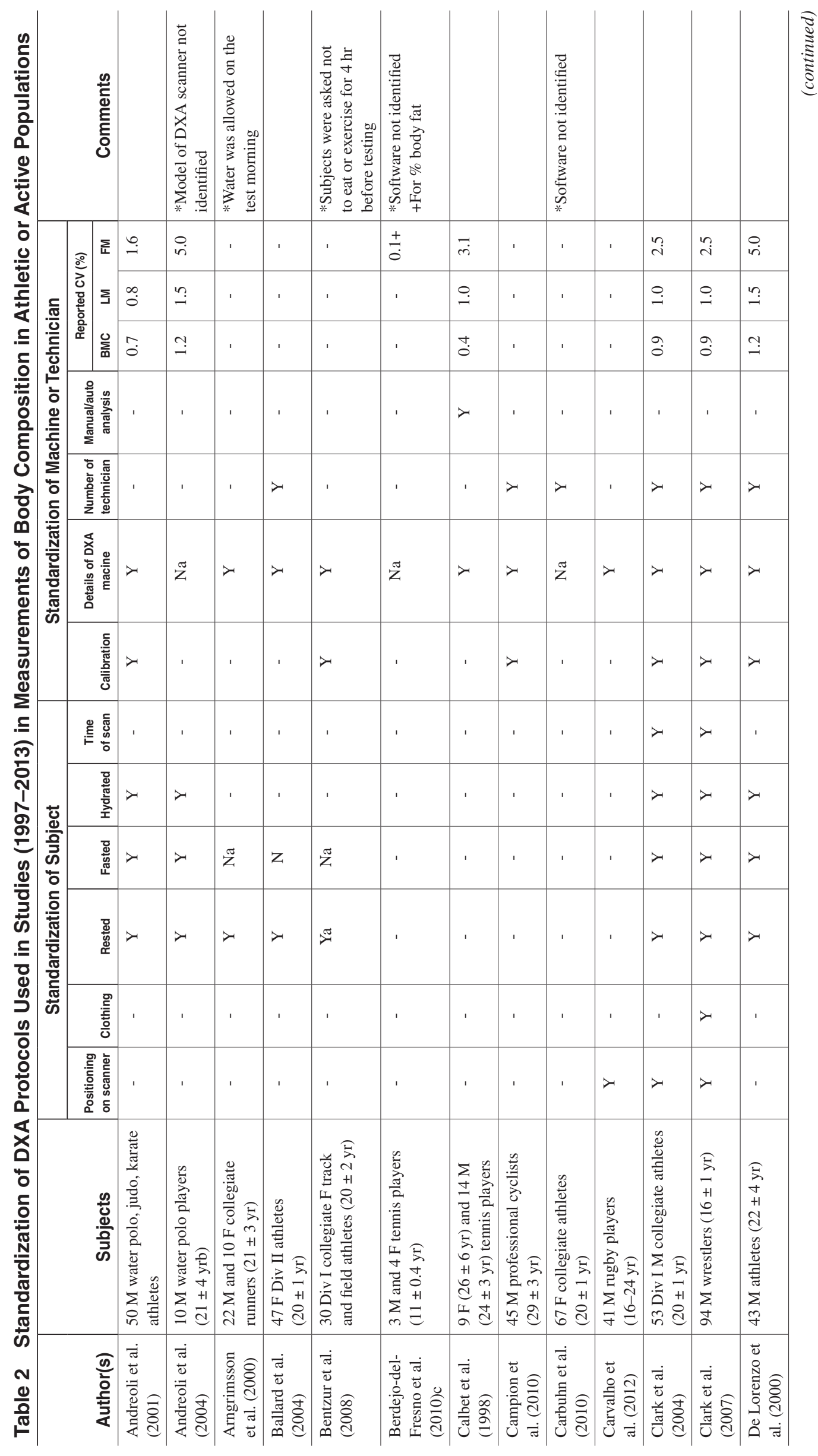




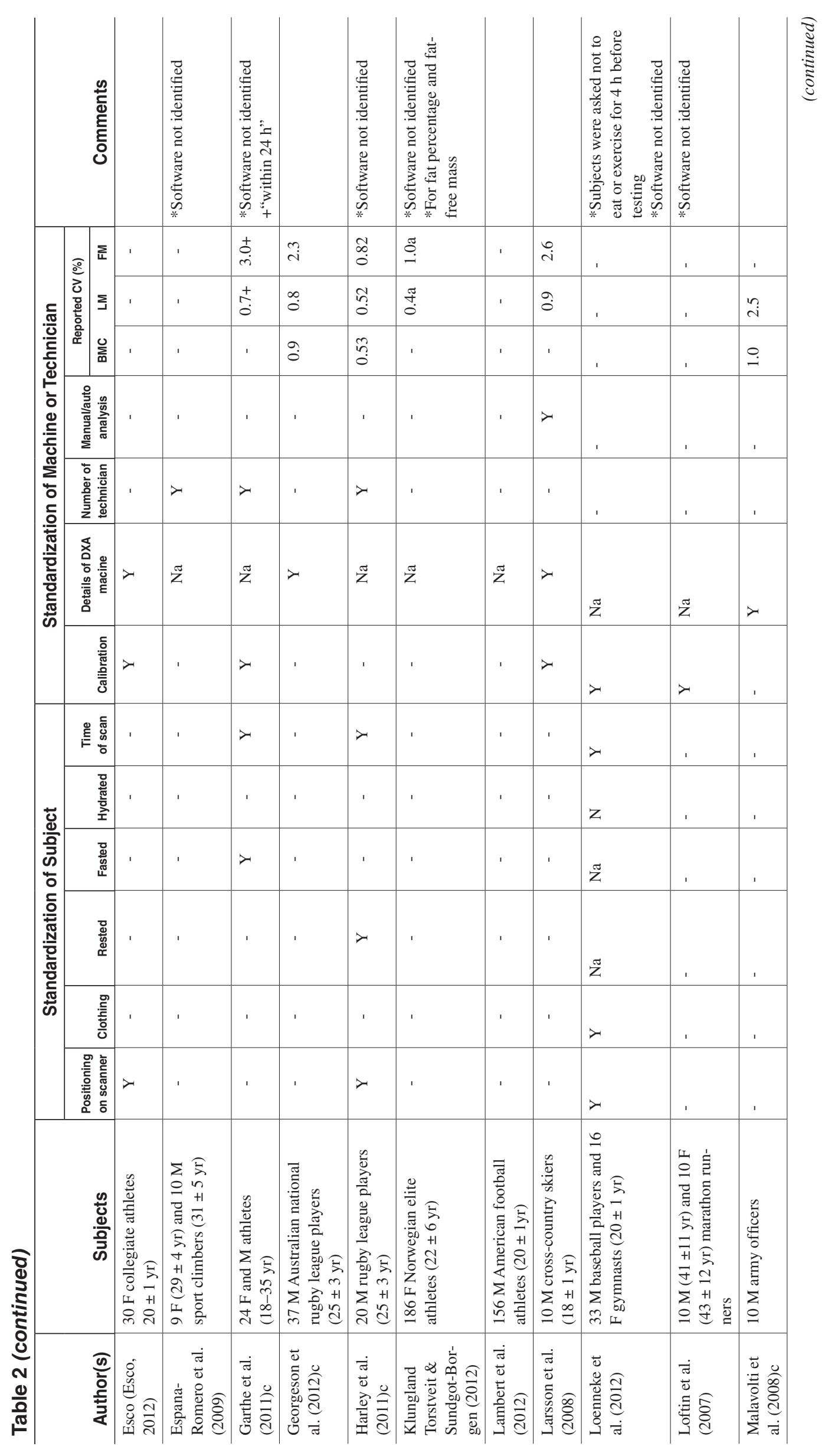

202 


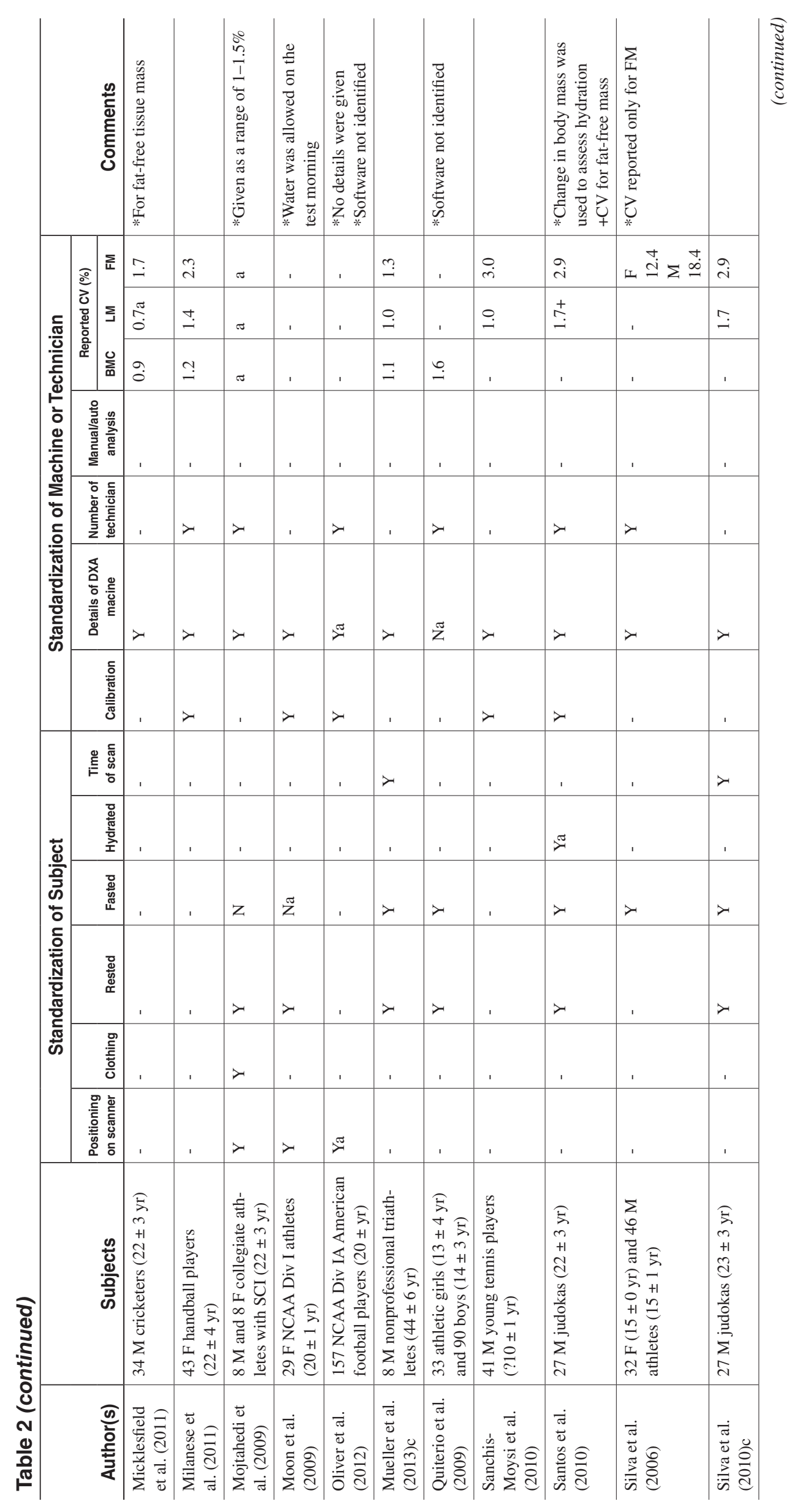

203 


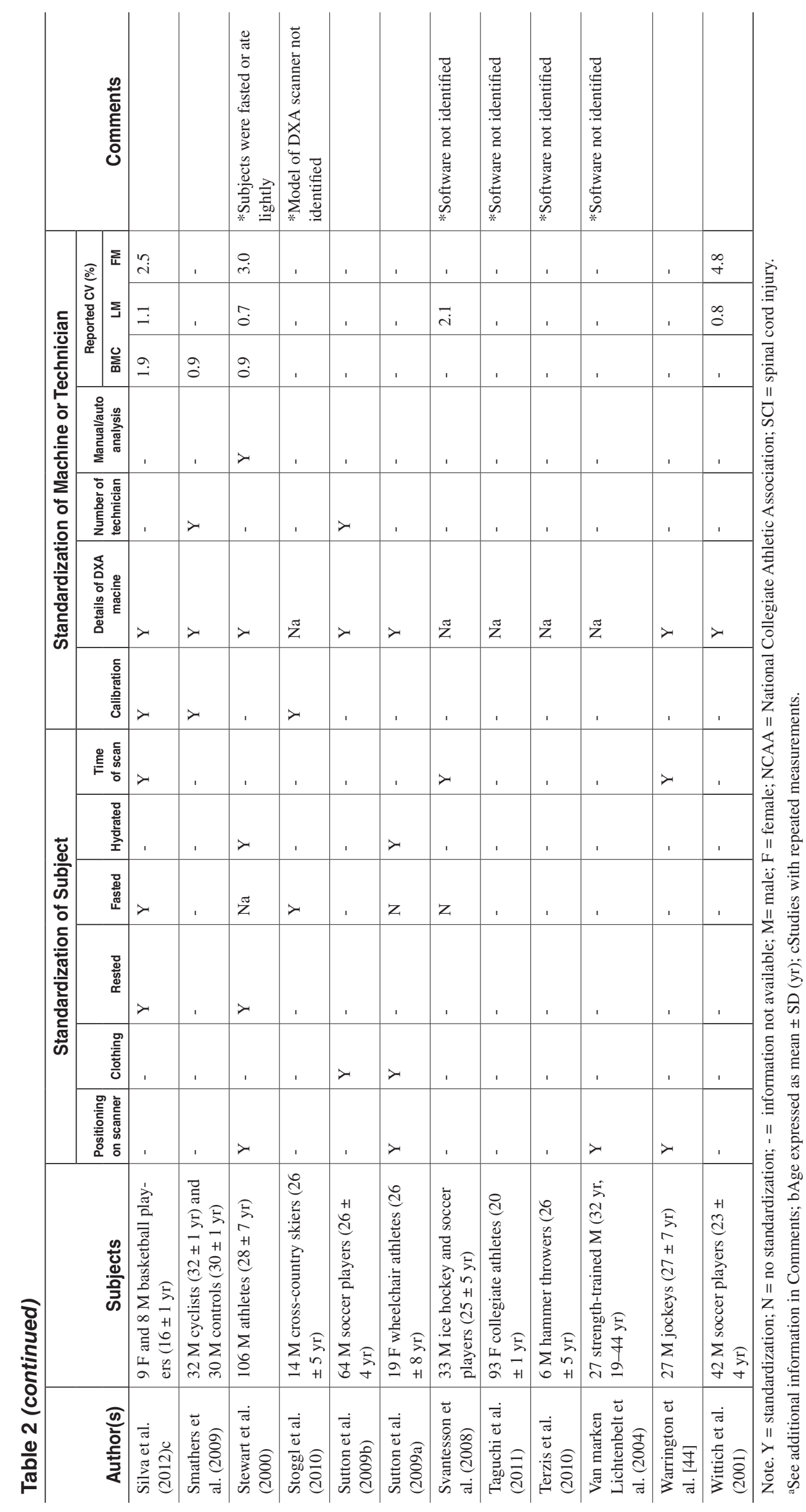




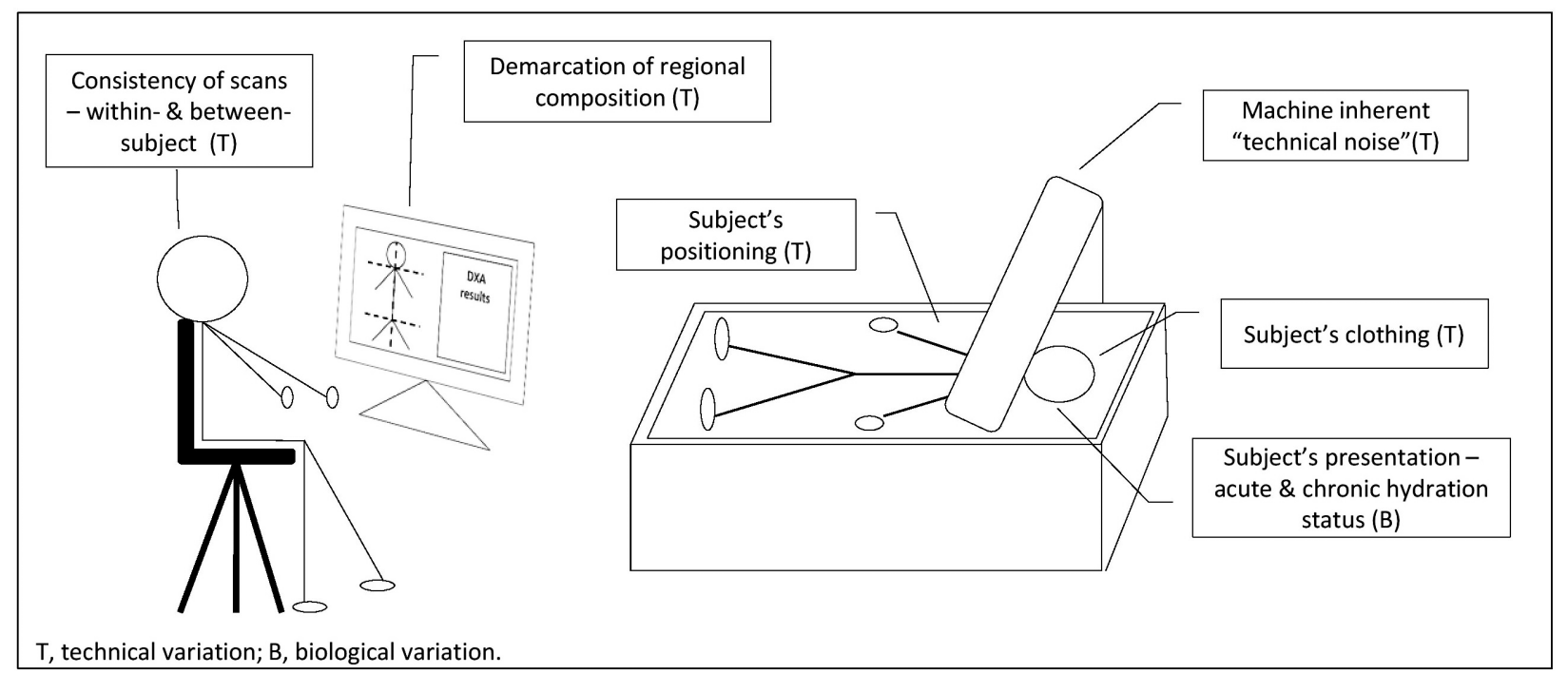

Figure 1 - Sources of variability or error associated with the processes of undertaking a DXA scan to measure body composition.

defined areas are superior in terms of reliability, as inconsistencies in placing the lines between each scan will alter regional body composition estimates (M. Lohman et al., 2009). Only one study has investigated this issue, and better reliability was found when regional measurements of two DXA scans were analyzed manually by one experienced technician (automatic $r=.74-0.98$ vs. manual $r=$.93-0.95) (M. Lohman et al., 2009).

Technician Error The experience or skill of the DXA technician on demarcation activities, or the number of technicians undertaking the scans are also potential sources of error in undertaking measures of regional body composition, but has received cursory attention. Good intertechnician reliability was demonstrated in a study where body composition estimates of manually drawn quadrilateral box around the L1-L4 region of interest (abdomen) of 43 scans were compared between the three operators (Glickman et al., 2004). Similar results were also observed in another study where high correlations within and between three trained technicians (with one of the technicians having less experience with this particular type of analysis) were found between manual segmentation of DXA scans of upper and lower extremities (Burkhart et al., 2009).

Clothing Other effects such as clothing have not been systematically examined and it is unclear if clothing items such as compression garments or cycling pants affect DXA reliability. Chemicals trapped in clothing (e.g., chlorine, salt water or sweat) may also alter the attenuation ratios of the DXA energies. Nevertheless, technical errors can be minimized by having meticulously standardized protocols for subject preparation and positioning, as well as the placement of segmental lines for postscan analysis of regional measurements of body composition.
Cross-Comparison Between DXA Machines A limitation of DXA is the difference in body composition estimates between DXA manufacturers (Pritchard et al., 1993; Soriano et al., 2004; Tothill et al., 2001), different beam technology within the same manufacturer (Clasey et al., 1997; Hull et al., 2009; Ioannidou et al., 2003), different machines (Oldroyd et al., 2003; Tothill et al., 2001), scan speed (fast, medium or slow scan mode) (Guo et al., 2004) and different software versions (Kistorp \& Svendsen, 1998; Van Loan et al., 1995). In fact, one study found small but significant differences in fat percentage between two Lunar prodigy machines (same software) when scanning soft tissue phantoms in different scan speeds (Guo et al., 2004).

For longitudinal studies where there is a change or upgrade in the system or software and results are compared with previous scans, a center-specific cross-calibration study is essential to obtain regression equations so that serial results can be accurately interpreted (Hull et al., 2009). This technique was demonstrated by Hull and colleagues (Hull et al., 2009) who compared measurements of body composition of 99 healthy subjects scanned by three DXA systems within a 3-hr period: a pencil-beam (Lunar DPXL) and two fan-beam scanners (Lunar Prodigy and iDXA). Differences in body composition estimates enabled calculation of translation regression equations between different systems. Although the development of specific translation regression equations is highly recommended, the ability to derive such equations may not be possible or practical in some settings. For example, the testing facility may not be able to accommodate two DXA machines at the same time. In such case, the authors recommended that their existing equations could be used (Hull et al., 2009). However, the use of these equations requires caution, as they were derived from a 
general population and likely to be inapplicable to the athletic populations who display different physiques. In fact, sex-differences in some measurements between systems have been found (Hull et al., 2009; Soriano et al., 2004). Therefore, derivation of regression equations should not only be center-specific, but also populationspecific.

Scanning Mode/Speed Currently, a typical DXA machine generally has three scan modes that adjust the X-ray attenuation for the thickness of each subject: thin $(<13 \mathrm{~cm})$, standard $(13-25 \mathrm{~cm})$, and thick $(>25$ $\mathrm{cm}$ ), although initially automatically determined by the software from the subject's body mass index (BMI), this can be overridden by the technician. Substantial changes in body composition, for example, a large increase in lean mass that leads to an increase in BMI, may lead to a change in scan mode/speed (e.g., from medium/standard to slow/thick scan mode). In such instances, it would be valuable to undertake two body composition scans under the different scan modes/speeds (i.e., in original and new mode) to allow better interpretation of changes in body composition. Furthermore, the impact of automatic or manual selection of scan mode/speed on body composition estimates by the analysis software based on the BMI to estimate body thickness is not known. This is of importance as muscular athletes with high body mass (e.g., a lean rugby player or rower weighing $>100 \mathrm{~kg}$ ) might be automatically scanned with slow/thick mode, however, others may argue that the standard or medium mode may be more appropriate.

\section{Biological Variation}

Effects of Daily Food and Fluid Intake Biological variation in DXA estimates are caused by factors related to subject presentation, including changes in tissue hydration, as well as gastrointestinal tract contents (the microbiome and undigested dietary components) (Horber et al., 1992; Thomsen et al., 1998; Vilaca et al., 2009). Earlier work found a significant increase in lean mass estimates when subjects drank a large amount of water (0.8-2.4 L) (Horber et al., 1992), consumed a meal (1039 g) (Thomsen et al., 1998), or underwent a dehydration-rehydration protocol (Going et al., 1993). However, the intake of food and fluid did not alter bone mineral and fat mass estimates. In contrast, no changes in body composition estimates were found when elderly subjects were scanned $1 \mathrm{hr}$ after a small meal $(50 \mathrm{~g}$ of bread roll with $6 \mathrm{~g}$ of margarine and $500 \mathrm{ml}$ of orange juice) (Vilaca et al., 2009).

Although the effects of food and fluid on body composition estimates are clearly demonstrated by such studies, the effect of meal size, composition of the meal and the timing of intake in relation to the DXA scan have not been thoroughly investigated in athletes. Our own laboratory determined the biological variability of DXA estimates of body composition of active people over the period of a day as well as the specific variability introduced by the consumption of food and fluid before an assessment (Nana et al., 2012a). We used a variety of meal volumes in an attempt to determine if there was a "maximum meal size" below which the measurement error was acceptable as well to determine whether a correction factor could be applied to results to account for the meal effect. Our results demonstrated that DXA was able to detect changes in total mass and lean mass that corresponded to the amount/weight of the meal consumed. However, the statistical model of different meal sizes (200- to 2000-ml meals) and variation in the time between breakfast and the repeat scan (e.g., 15-60 min) was unable to "adjust" for changes in DXA estimates of regional body composition. The inability to detect a uniform or adjustable error in these estimates suggests a complicated interaction between food/fluid consumption and DXA assessments of body composition, based on a variety of factors, such as the size, timing and composition of a meal, individual variability in rate of digestion and absorption of food and fluid, and the potential effect of gastrointestinal gas after food consumption. Therefore, to maximize the precision of whole body DXA scans, subjects should present in a fasted state, and ideally in a standardized state of hydration and given the impact of food and after evacuation of bowels and bladder, given the impact of acute food/ fluid intake, it is likely that bowel and bladder contents also influence results.

Effects of Exercise Sessions DXA technology assumes that soft tissues are normally hydrated for accurate partitioning into fat and lean fractions (Laskey, 1996; Plank, 2005). It assumes that there is a constant and uniform fat-free mass hydration of $73 \%$ (Pietrobelli et al., 1998), however, a review by Lohman et al. (T. G. Lohman et al., 2000) suggested that the hydration of fat-free mass in humans can range between $72-74.5 \%$, whereas earlier work (Moore \& Boyden, 1963) found a larger variation in hydration between $67-85 \%$. These variations would be expected to cause detectable variability in estimation of fat-free mass.

Of particular relevance to athletic populations is the effect of exercise on whole body or tissue hydration status; this includes the effects of exercise per se, but must in practical terms, also include the effects of the food or fluid intake that is characteristically undertaken before and during the session. Changes in hydration may arise from loss (sweating) or gain (drinking) of fluid before, during or after exercise, as well as the effect of exerciseassociated fluid shifts between body compartments, or the expansion/reduction of body fluid compartments as a result of dehydration and/or increased blood flow and capillary dilation (Coyle, 2004; Maughan et al., 2007; Sawka et al., 2007). These characteristics have not been systematically examined.

Our group has undertaken simple studies of the effect of exercise on DXA estimates of body composition. These observations were made under free-living conditions, allowing subjects to consume ad libitum amounts of food 
and fluid before and during the exercise session according to their usual practices, with exercise protocols also ranging in duration and intensity. We found that cycling or resistance-training produced detectable changes in estimates of body composition, with the small net changes in total mass and lean mass reflecting the ability of subjects to match fluid intake (increase DXA estimates of fat-free mass) with sweat loss (decrease DXA estimates of fat-free mass) during the sessions.

Although most of the changes in estimates of total mass and lean mass were trivial, changes in regional estimates following an exercise session were worth noting. Specifically, the reduction in trunk estimates in conjunction with a gain in leg and arm mass observed in male cyclists are thought to be due, at least partially, to the effect of recompartmentalization of body fluids. This physiological change is common among cyclists and refers to the shunting of blood volume from the trunk to the periphery (Montain, 1992; Rowell, 2004). Changes in regional body composition estimates were also observed in strength-trained subjects where there was a substantial increase in total arm mass and arm lean mass estimates. These changes could reflect shifts in blood volume to the upper body as a result of the type of exercise (e.g., upper body exercise) undertaken by the subjects in conjunction with the absorption and distribution of food and fluid intake. Furthermore, Going et al. (Going et al., 1993) speculated that shifts in fluid compartments may in fact affect attenuation ratios. To minimize this source of variability in DXA estimates of body composition in a practical way, scans should be done before any exercise is undertaken for the day.

Although these recommendations for standardized DXA scanning protocols will reduce measurement error, future studies are needed to investigate other sources of day-to-day biological variability. Factors of interest include periods of greater extremes of energy expenditure and intake, tracking of menstrual status, acute and chronic changes in hydration status, alterations in gastrointestinal content (e.g., effects of high fiber and low residue diets) and gas, and manipulation of intramuscular solutes (e.g., glycogen, creatine, carnosine) and their associated water binding. Sources of known and possible biological and technical variations are summarized in Figure 1.

\section{Applications of DXA in Subpopulations}

\section{Scanning Techniques to Accommodate Tall and/or Broad Subjects}

DXA is primarily applied in a clinical setting to measure bone mineral density for the diagnosis of low bone mass and osteoporosis. The physical characteristics of a DXA machine are therefore designed to reflect both its primary purpose (to measure specific bone sites) and the targeted population (the elderly). For these reasons, typical dimensions of the scanning beds of current DXA models are approximately 60-66 cm wide by 190-198 $\mathrm{cm}$ long (Silva et al., 2013). This is clearly problematic when DXA is used for a whole body scan of individuals who are taller and/or broader than the scanning area. The inability of DXA to accommodate such physiques not only limits its use as a physique assessment tool, but also presents a source of sampling bias because subjects with such physiques would be automatically excluded from research studies in which DXA is used to assess physique traits.

Previous studies have examined scanning techniques to accommodate tall (Evans et al., 2005; Santos et al., 2012) or broad subjects (Rothney et al., 2009), including scanning tall subjects with the exclusion of the head or feet, or scanning with bent knees to allow both the head and feet to be included in the scan (Silva et al., 2004). Another alternative is to sum two partial scans, with preference given to dividing the body at the neck rather than at the hip (Evans et al., 2005).

Only one study has investigated techniques to accommodate both tall and broad subjects (e.g., as found in sports such as rowing or rugby codes) which involved summing of partial scans on both the horizontal and vertical planes (Nana et al., 2012b). An important finding from this study was that there are substantial errors associated with the summation of partial scans to simulate tall subjects, due to errors associated with measurement of an isolated "head" scan (i.e., DXA estimates from menton to chin). It is likely that these errors occur because of assumptions that are included in the machine algorithm to include the fat content of the head, which cannot be directly measured behind the bone shadow of the skull.

It is unclear if this error is limited to Lunar Prodigy scanners because it has not been reported in other studies using current models of Hologic scanners which scan "up and down" versus "transverse" in the Lunar Prodigy (Evans et al., 2005; Santos et al., 2012). Specifically, the technician should initiate a scan with one sweep to create an empty gap and pause, then reposition the subject on the scanning bed ensuring that their feet are within the scanning area before resuming the scan with the inclusion of the head region as much as possible. This scanning technique, although causing part of the head to be occluded, ensures that the whole-body composition attenuation algorithm is maximized (head region is required to calculate body composition estimates of the whole body) (Taylor et al., 1997).

Depending on the software, the calculation of body composition estimates from partial scans may involve manual addition of body parts (e.g., arm lean + leg lean + trunk lean) and therefore increase technician burden. Moreover, the increased number of DXA scans per assessment to accommodate broad subjects will lead to increased overall radiation exposure per year (particularly with longitudinal monitoring over time) and could be significant for athletes who are already exposed to ionizing radiation from other diagnostic imaging techniques and 
extensive aeroplane traveling (Cross et al., 2003; Orchard et al., 2005). Therefore, all of the above-mentioned factors such as reliable scanning techniques to accommodate tall and/or broad subjects, and their subsequent increased in scanning time, potential cost, radiation exposure and frequency of scans are needed to be taken into account when undertaking body composition assessment by DXA in individuals with extreme physiques.

\section{Athletes With Disability}

DXA can be used to assess body composition in a range of parasport classifications, including athletes with spinal cord injury (Mojtahedi et al., 2009; Sutton et al., 2009b); however, DXA is not suitable for athletes with tremors or spasticity. Body composition estimates generated by DXA also have a role in the application of biomechanics analysis. For example, in lower leg amputee athletes, DXA can be used to estimate the mass of the proximal segments and stump and their respective center of mass. This information enables the determination of inertial properties of the segments of those limbs and consequently the net muscle torques around the lower limb joints during running. In addition, detailed body composition information generated can also provide information on symmetry/imbalance between left and right sides of each body region (applicable to all athletes). Depending on the type of impairment, slight alteration in scanning techniques may be necessary. For example, the use of positioning aids, special strapping or even the placement of towels to support limbs can be used. Technicians are encouraged to document carefully any changes from the scanning and analyzing (e.g., custom region of interest) protocols and the ability to repeat these techniques are essential in enhancing the consistency in subject positioning and therefore whole and regional body composition estimates in subsequent scans.

\section{The Best Practice Protocol for the Assessment of Whole Body Composition by DXA}

The previous discussions have made clear that a standardized protocol for the use of DXA to measure body composition of athletes is warranted, but there is an absence of a universal approach to this need. We offer a best practice protocol of DXA body composition assessment suitable for use in a real-life athlete setting, with a known reliability which has been optimized in terms of the balance between the effort required to achieve it and the benefits of its precision. This protocol, presented in Table 3, was developed from first principles, in conjunction with pilot work and a series of studies of sources of measurement variability.

Although this protocol ensures maximum precision, it poses some practical costs and burden on both the athletes and the technician that need to be balanced against the potential value of the additional precision gained. Our own experiences have provided evidence of the benefits of enhanced precision in an athletic setting whereby novel findings of changes in body composition following an intervention were detected with our Best Practice Protocol but would have been missed with the increased measurement noise associated with a less systematic scanning protocol (Nana et al., in review)

The Best Practice Protocol should be considered a recommended standard until future work allows further refinements to be made. Furthermore, studies which involve DXA measurements of body composition should report details of how their scanning techniques conform to this or other standardization procedures, with Table 4 summarizing characteristics of importance that should be noted. Laboratories are encouraged to determine their own measurement error and cite it within such reports. 


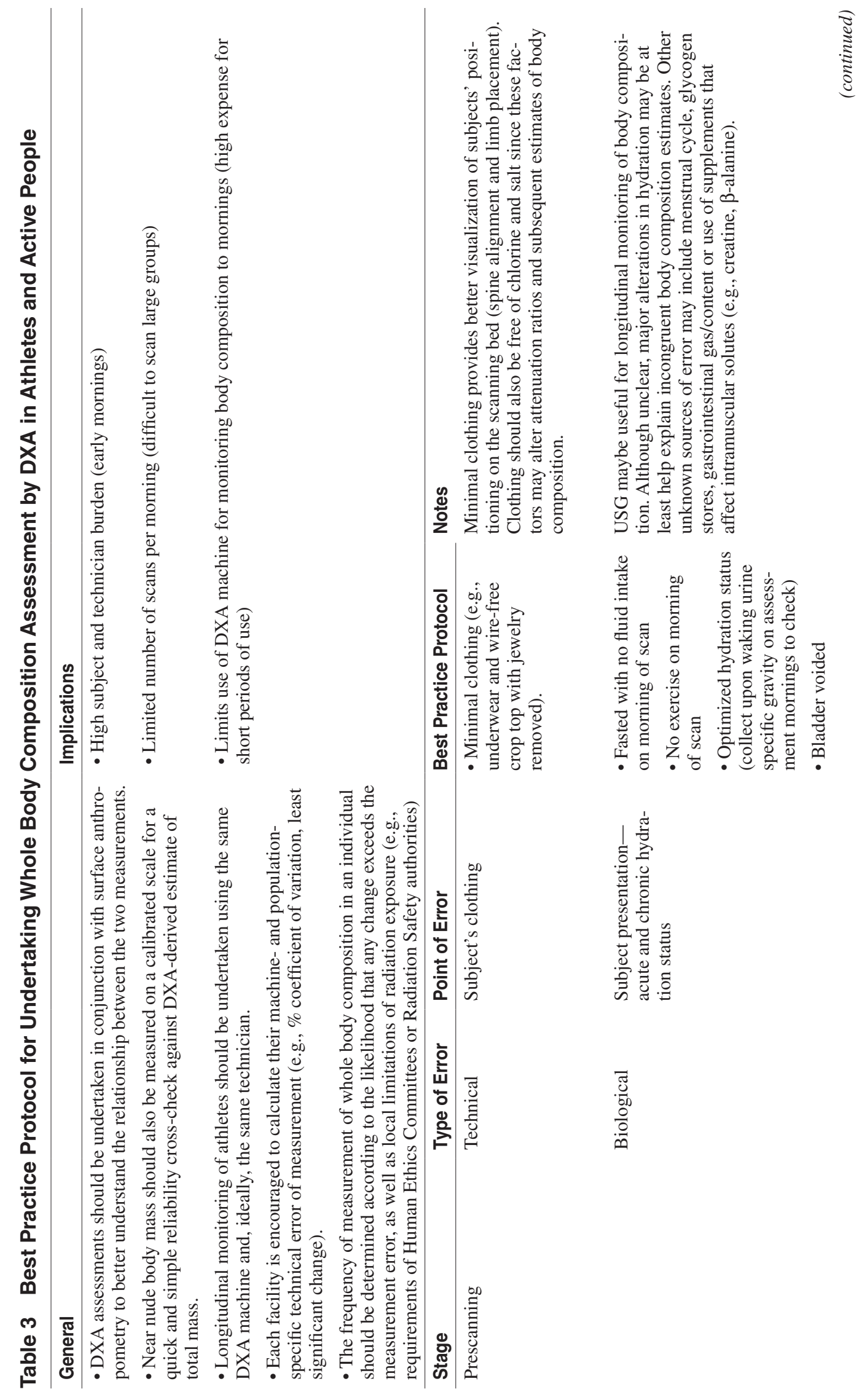




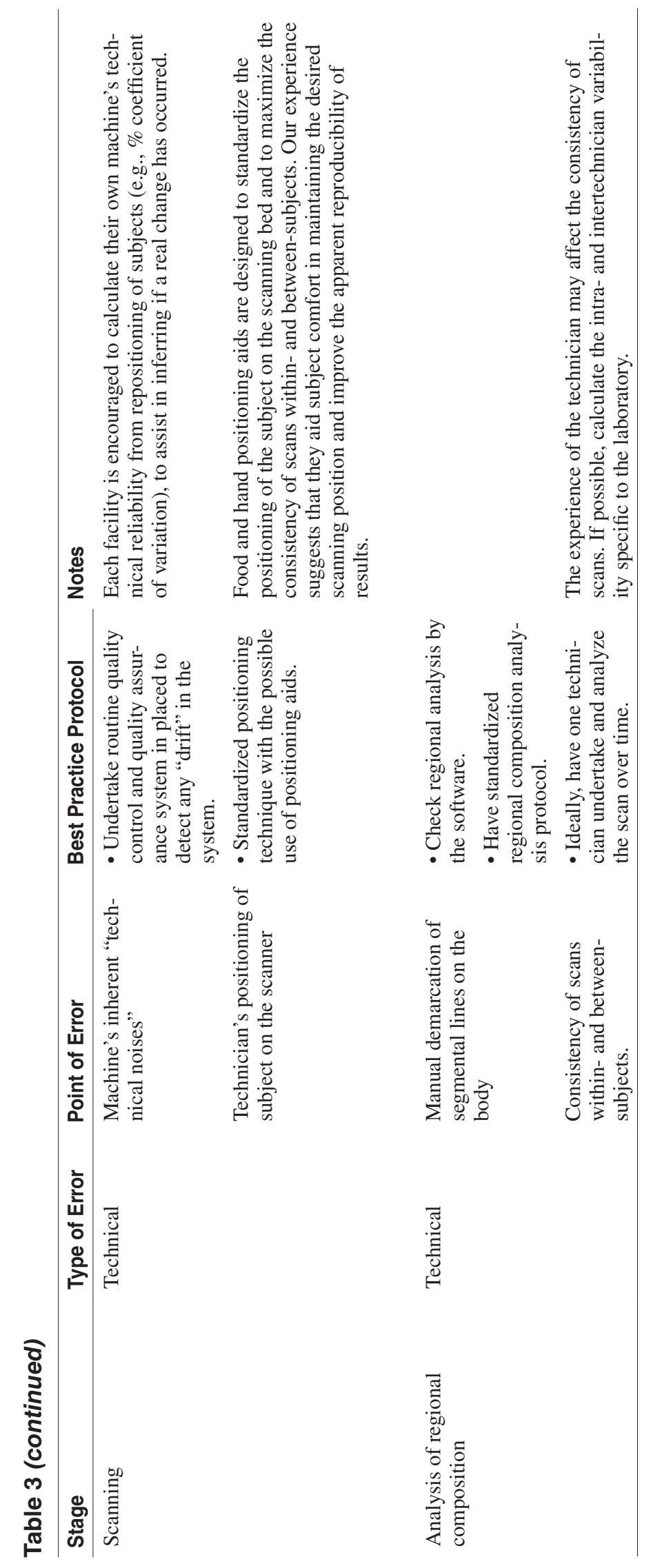


Table 4 Information that Should be Included in Reports of Study Methodology When Using DXA to Estimate Body Composition in Athletes and Active People

\begin{tabular}{|c|c|}
\hline Themes & Reporting Conditions \\
\hline \multirow[t]{5}{*}{ Subject presentation } & - Fasting state \\
\hline & - Resting state \\
\hline & - Hydration status \\
\hline & - Bladder voided or not \\
\hline & - Clothing \\
\hline \multirow[t]{6}{*}{ DXA instrument } & - Brand \\
\hline & - Model \\
\hline & - Beam configuration \\
\hline & - Analysis software version \\
\hline & - Scanning mode \\
\hline & $\begin{array}{l}\text { - Machine's technical reliability calculated from repositioning of subjects (e.g., \% } \\
\text { coefficient of variation) }\end{array}$ \\
\hline \multirow[t]{4}{*}{ Positioning and analysis protocol } & $\begin{array}{l}\text { - Description of how the subjects are positioned on the scanning bed including hand } \\
\text { and feet positioning (and with/without the use of positioning aids) }\end{array}$ \\
\hline & $\begin{array}{l}\text { - If regional composition is reported-report the analysis technique (e.g., fully auto- } \\
\text { matic by the software, automatic by the software and confirmed by the technician, or } \\
\text { manual analysis by the technician) }\end{array}$ \\
\hline & - Detailed description of any custom region of interest \\
\hline & $\begin{array}{l}\text { - Specific techniques used to scan subpopulations (e.g., tall and/or broad subjects, } \\
\text { athletes with disability) }\end{array}$ \\
\hline \multirow{2}{*}{$\begin{array}{l}\text { Number of technicians undertaking } \\
\text { scans (especially for longitudinal } \\
\text { monitoring) }\end{array}$} & - The number of technicians involved \\
\hline & - Each technician's role (e.g., scanning, analyzing or both scanning and analysis) \\
\hline
\end{tabular}

\section{Summary}

Athletes and coaches demand physiological and performance data to be as accurate as possible to inform training-related decisions. With the proliferation of DXA scanning being used in elite sport, this demand is increasingly embracing body composition measures. Historically, DXA scan data which have been less rigorously acquired are likely to be less accurate, purely as a result of the lack of awareness of the additive errors involved, and could easily fall prey to being "overinterpreted" as being more accurate than they really are. While the demands of sport increasingly strive for better data, the contribution of a best practice scan protocol is likely to serve the interests of the scientist, coach, and athlete alike.

\section{Acknowledgments}

Manuscript preparation was undertaken by AN, GS, AS and LB. All authors approved the final version of the paper.

\section{References}

Ackland, T.R., Lohman, T.G., Sundgot-Borgen, J., Maughan, R.J., Meyer, N.L., Stewart, A.D., \& Muller, W. (2012). Current status of body composition assessment in sport: review and position statement on behalf of the ad hoc research working group on body composition health and performance, under the auspices of the I.O.C. Medical Commission. Sports Medicine (Auckland, N.Z.), 42, 227-249. PubMed doi:10.2165/11597140-00000000000000

Andreoli, A., Monteleone, M., Van Loan, M., Promenzio, L., Tarantino, U., \& De Lorenzo, A. (2001). Effects of different sports on bone density and muscle mass in highly trained athletes. Medicine \& Science in Sports \& Exercise, 33, 507-511.

Andreoli, A., Melchiorri, G., Volpe, S. L., Sardella, F., Iacopino, L., \& De Lorenzo, A. (2004). Multicompartment model to assess body composition in professional water polo players. The Journal of Sports Medicine and Physical Fitness, 44, 38-43. 
Andreoli, A., Scalzo, G., Masala, S., Tarantino, U., \& Guglielmi, G. (2009). Body composition assessment by dual-energy X-ray absorptiometry (DXA). La Radiologia Medica, 114, 286-300. PubMed doi:10.1007/s11547-009-0369-7

Arngrimsson, S., Evans, E.M., Saunders, M.J., Ogburn, C.L., 3rd, Lewis, R.D., \& Cureton, K.J. (2000). Validation of body composition estimates in male and female distance runners using estimates from a fourcomponent model. American Journal of Human Biology, 12, 301-314. PubMed doi:10.1002/(SICI)15206300(200005/06)12:3<301::AID-AJHB1>3.0.CO;2-J

Ballard, T. P., Fafara, L., \& Vukovich, M. D. (2004). Comparison of Bod Pod and DXA in female collegiate athletes. Medicine \& Science in Sports \& Exercise, 36, 731-735.

Bentzur, K. M., Kravitz, L., \& Lockner, D. W. (2008). Evaluation of the BOD POD for estimating percent body fat in collegiate track and field female athletes: A comparison of four methods. The Journal of Strength \& Conditioning Research, 22, 1985-1991.

Berdejo-del-Fresno, D., Vicente-Rodriguez, G., González-Ravé, J. M., Moreno, L., \& Rey-López, J. P. (2010). Body composition and fitness in elite spanish children tennis players. Journal of Human Sport and Exercise (online), 5, 250-264

Burkhart, T.A., Arthurs, K.L., \& Andrews, D.M. (2009). Manual segmentation of DXA scan images results in reliable upper and lower extremity soft and rigid tissue mass estimates. Journal of Biomechanics, 42, 1138-1142. PubMed doi:10.1016/j.jbiomech.2009.02.017

Calbet, J. A., Moysi, J. S., Dorado, C., \& Rodriguez, L. P. (1998). Bone mineral content and density in professional tennis players. Calcified Tissue International, 62, 491-496.

Campion, F., Nevill, A. M., Karlsson, M. K., Lounana, J., Shabani, M., Fardellone, P., et al. (2010). Bone status in professional cyclists. International Journal of Sports Medicine, 31, 511-515.

Carbuhn, A. F., Fernandez, T. E., Bragg, A. F., Green, J. S., \& Crouse, S. F. (2010). Sport and training influence bone and body composition in women collegiate athletes. The Journal of Strength \& Conditioning Research, 24, 1710-1717.

Carvalho, H. M., Coelho-e-Silva, M. J., Franco, S., Figueiredo, A. J., Tavares, O. M., Ferry, B., et al. (2012). Agreement between anthropometric and dual-energy X-ray absorptiometry assessments of lower-limb volumes and composition estimates in youth-club rugby athletes. Applied Physiology, Nutrition, and Metabolism, 37, 463-471.

Clark, R. R., Bartok, C., Sullivan, J. C., \& Schoeller, D. A. (2004). Minimum weight prediction methods cross-validated by the four-component model. Medicine \& Science in Sports \& Exercise, 36, 639-647

Clark, R.R., Sullivan, J.C., Bartok, C.J., \& Carrel, A.L. (2007), DXA provides a valid minimum weight in wrestlers. Medicine and Science in Sports and Exercise, 39, 2069-2075. PubMed doi:10.1249/mss.0b013e31814fb423

Clasey, J.L., Hartman, M.L., Kanaley, J., Wideman, L., Teates, C.D., Bouchard, C., .\& Weltman, A. (1997). Body composition by DEXA in older adults: accuracy and influence of scan mode. Medicine and Science in Sports and Exercise, 29, 560-567. PubMed doi:10.1097/00005768-19970400000020
Coyle, E.F. (2004). Fluid and fuel intake during exercise. Journal of Sports Sciences, 22, 39-55. PubMed doi:10.1080/0264041031000140545

Cribb, P.J., \& Hayes, A. (2006). Effects of supplement timing and resistance exercise on skeletal muscle hypertrophy. Medicine and Science in Sports and Exercise, 38, 1918-1925. PubMed doi:10.1249/01.mss.0000233790. $08788.3 \mathrm{e}$

Cross, T.M., Smart, R.C., \& Thomson, J.E. (2003). Exposure to diagnostic ionizing radiation in sports medicine: assessing and monitoring the risk. Clinical Journal of Sport Medicine, 13, 164-170. PubMed doi:10.1097/00042752200305000-00007

De Lorenzo, A., Andreoli, A., \& Candeloro, N. (1997). Withinsubject variability in body composition using dual-energy X-ray absorptiometry. Clinical Physiology (Oxford, England), 17, 383-388. PubMed doi:10.1046/j.13652281.1997.04242.x

Duz, S., Kocak, M., \& Korkusuz, F. (2009). Evaluation of body composition using three different methods compared to dual-energy X-ray absorptiometry. European Journal of Sport Science, 9, 181-190. doi:10.1080/17461390902763425

Evans, E.M., Prior, B.M., \& Modlesky, C.M. (2005). A mathematical method to estimate body composition in tall individuals using DXA. Medicine and Science in Sports and Exercise, 37, 1211-1215. PubMed doi:10.1249/01. mss.0000170077.87301.65

De Lorenzo, A., Bertini, I., Iacopino, L., Pagliato, E., Testolin, C., \& Testolin, G. (2000). Body composition measurement in highly trained male athletes. A comparison of three methods. The Journal of Sports Medicine and Physical Fitness, 40, 178-183.

Esco, M. R. (2013). The accuracy of the body adiposity index for predicting body fat percentage in collegiate female athletes. The Journal of Strength \& Conditioning Research, 27, 1679-1683.

Espana Romero, V., Ruiz, J. R., Ortega, F. B., Artero, E. G., Vicente-Rodriguez, G., Moreno, L. A., et al. (2009). Body fat measurement in elite sport climbers: comparison of skinfold thickness equations with dual energy X-ray absorptiometry. Journal of Sports Science and Medicine, 27, 469-477.

Garthe, I., Raastad, T., \& Sundgot-Borgen, J. (2011). Long-term effect of weight loss on body composition and performance in elite athletes. International Journal of Sport Nutrition and Exercise, 21, 426-435.

Georgeson, E. C., Weeks, B. K., McLellan, C., \& Beck, B. R. (2012). Seasonal change in bone, muscle and fat in professional rugby league players and its relationship to injury: A cohort study. BMJ Open, 2.

Glickman, S.G., Marn, C.S., Supiano, M.A., \& Dengel, D.R. (2004). Validity and reliability of dual-energy X-ray absorptiometry for the assessment of abdominal adiposity. Journal of Applied Physiology (Bethesda, Md.), 97, 509-514. PubMed

Going, S.B., Massett, M.P., Hall, M.C., Bare, L.A., Root, P.A. Williams, D.P., .... (1993). Detection of small changes in body composition by dual-energy $\mathrm{x}$-ray absorptiometry. 
The American Journal of Clinical Nutrition, 57, 845-850. PubMed

Guo, Y., Franks, P.W., Brookshire, T., \& Antonio Tataranni, P. (2004). The intra- and inter-instrument reliability of DXA based on ex vivo soft tissue measurements. Obesity Research, 12, 1925-1929. PubMed doi:10.1038/ oby. 2004.241

Harley, J. A., Hind, K., \& O'Hara J, P. (2011). Three-compartment body composition changes in elite rugby league players during a super league season, measured by dualenergy X-ray absorptiometry. Journal of Strength and Conditioning Research, 25, 1024-1029. PubMed doi:10.1519/ JSC.0b013e 3181cc21fb

Hopkins, W.G. (2000). Measures of reliability in sports medicine and science. Sports Medicine (Auckland, N.Z.), 30 1-15. PubMed doi:10.2165/00007256-200030010-00001

Horber, F.F., Thomi, F., Casez, J.P., Fonteille, J., \& Jaeger, P. (1992). Impact of hydration status on body composition as measured by dual energy X-ray absorptiometry in normal volunteers and patients on haemodialysis. The British Journal of Radiology, 65, 895-900. PubMed doi:10.1259/0007-1285-65-778-895

Hull, H., He, Q., Thornton, J., Javed, F., Allen, L., Wang, J., . ... (2009). iDXA, Prodigy, and DPXL dual-energy X-ray absorptiometry whole-body scans: a cross-calibration study. Journal of Clinical Densitometry, 12, 95-102. PubMed doi:10.1016/j.jocd.2008.09.004

Ioannidou, E., Padilla, J., Wang, J., Heymsfield, S.B., Thornton, J.C., Horlick, M., . . .. (2003). Pencil-beam versus fan-beam dual-energy X-ray absorptiometry comparisons across four systems: appendicular lean soft tissue. Acta Diabetologica, 40(Suppl. 1), S83-S85. PubMed doi:10.1007/s00592-003-0034-x

Kistorp, C.N., \& Svendsen, O.L. (1998). Body composition results by DXA differ with manufacturer, instrument generation and software version. Applied Radiation and Isotopes, 49, 515-516. PubMed doi:10.1016/S0969. 8043(97)00063-8

Kohrt, W.M. (1995). Body composition by DXA: tried and true? Medicine and Science in Sports and Exercise, 27, 1349-1353. PubMed doi:10.1249/00005768-19951000000001

Klungland Torstveit, M., \& Sundgot-Borgen, J. (2012). Are under- and overweight female elite athletes thin and fat? A controlled study. Medicine \& Science in Sports \& Exercise, 44, 949-957.

LaForgia, J., Dollman, J., Dale, M.J., Withers, R.T., \& Hill, A.M. (2009). Validation of DXA body composition estimates in obese men and women. Obesity (Silver Spring, Md.), 17, 821-826. PubMed doi:10.1038/oby.2008.595

Lambert, B. S., Oliver, J. M., Katts, G. R., Green, J. S., Martin, S. E., \& Crouse, S. F. (2012). DEXA or BMI: clinical considerations for evaluating obesity in collegiate division I-A American football athletes. Clinical Journal of Sport Medicine, 22, 436-438.

Lambrinoudaki, I., Georgiou, E., Douskas, G., Tsekes, G., Kyriakidis, M., \& Proukakis, C. (1998). Body composition assessment by dual-energy $\mathrm{x}$-ray absorptiometry: comparison of prone and supine measurements. Metabo- lism: Clinical and Experimental, 47, 1379-1382. PubMed doi:10.1016/S0026-0495(98)90309-2

Larsson, P., \& Henriksson-Larsen, K. (2008). Body composition and performance in cross-country skiing. International Journal of Sports Medicine, 29, 971-975.

Laskey, M.A. (1996). Dual-energy X-ray absorptiometry and body composition. Nutrition (Burbank, Los Angeles County, Calif.), 12, 45-51. PubMed doi:10.1016/0899-9007(95)00017-8

Lohman, M., Tallroth, K., Kettunen, J.A., \& Marttinen, M.T. (2009). Reproducibility of dual-energy x-ray absorptiometry total and regional body composition measurements using different scanning positions and definitions of regions. Metabolism: Clinical and Experimental, 58, 1663-1668. PubMed doi:10.1016/j.metabol.2009.05.023

Lohman, T.G., Harris, M., Teixeira, P.J., \& Weiss, L. (2000). Assessing body composition and changes in body composition. Another look at dual-energy X-ray absorptiometry. Annals of the New York Academy of Sciences, 904, 45-54. PubMed doi:10.1111/j.1749-6632.2000.tb06420.x

Madsen, O.R., Jensen, J.E., \& Sorensen, O.H. (1997). Validation of a dual energy X-ray absorptiometer: measurement of bone mass and soft tissue composition. European Journal of Applied Physiology and Occupational Physiology, 75, 554-558. PubMed doi:10.1007/s004210050204

Malavolti, M., Battistini, N. C., Dugoni, M., Bagni, B., Bagni, I., \& Pietrobelli, A. (2008). Effect of intense military training on body composition. The Journal of Strength \& Conditioning Research, 22, 503-508.

Margulies, L., Horlick, M., Thornton, J.C., Wang, J., Ioannidou, E., \& Heymsfield, S.B. (2005). Reproducibility of pediatric whole body bone and body composition measures by dual-energy X-ray absorptiometry using the GE Lunar Prodigy. Journal of Clinical Densitometry, 8, 298-304. PubMed doi:10.1385/JCD:8:3:298

Maughan, R.J., Shirreffs, S.M., \& Watson, P. (2007). Exercise, heat, hydration and the brain. Journal of the American College of Nutrition, 26, 604S-612S. PubMed doi:10.10 80/07315724.2007.10719666

Mazess, R.B., Barden, H.S., Bisek, J.P., \& Hanson, J. (1990). Dual-energy $\mathrm{x}$-ray absorptiometry for total-body and regional bone-mineral and soft-tissue composition. The American Journal of Clinical Nutrition, 51, 1106-1112. PubMed

Meyer, N.L., Sundgot-Borgen, J., Lohman, T.G., Ackland, T.R., Stewart, A.D., Maughan, R.J., . . .. (2013). Body composition for health and performance: a survey of body composition assessment practice carried out by the Ad Hoc Research Working Group on Body Composition, Health and Performance under the auspices of the IOC Medical Commission. British Journal of Sports Medicine, 47, 1044-1053. PubMed doi:10.1136/bjsports-2013092561

Micklesfield, L. K., Gray, J., \& Taliep, M. S. (2012). Bone mineral density and body composition of South African cricketers. Journal of Bone and Mineral Metabolism, 30, 232-237.

Milanese, C., Piscitelli, F., Lampis, C., \& Zancanaro, C. (2011). Anthropometry and body composition of female handball players according to competitive level or the playing 
position. Journal of Sports Science and Medicine, 29, 1301-1309.

Mojtahedi, M.C., Valentine, R.J., \& Evans, E.M. (2009). Body composition assessment in athletes with spinal cord injury: comparison of field methods with dual-energy X-ray absorptiometry. Spinal Cord, 47, 698-704. PubMed doi:10.1038/sc.2009.20

Montain, S. J. C., E. F. (1992). Fluid ingestion during exercise increases skin blood flow independent of increases in blood volume. Journal of Applied Physiology (Bethesda, Md.), 73, 903-910. PubMed

Moon, J.R., Eckerson, J.M., Tobkin, S.E., Smith, A.E., Lockwood, C.M., Walter, A.A., . . .. (2009). Estimating body fat in NCAA Division I female athletes: a five-compartment model validation of laboratory methods. European Journal of Applied Physiology, 105, 119-130. PubMed doi:10.1007/s00421-008-0881-9

Moore, F.D., \& Boyden, C.M. (1963). Body cell mass and limits of hydration of the fat-free body: Their relation to estimated skeletal weight. Annals of the New York Academy of Sciences, 110, 62-71. PubMed doi:10.1111/j.1749-6632.1963.tb17072.x

Mueller, S.M., Anliker, E., Knechtle, P., Knechtle, B., \& Toigo, M. (2013). Changes in body composition in triathletes during an Ironman race. European Journal of Applied Physiology, 113, 2343-2352. PubMed doi:10.1007/ s00421-013-2670-3

Nana, A., Slater, G.J., Hopkins, W.G., \& Burke, L.M. (2012a). Effects of daily activities on DXA measurements of body composition in active people. Medicine and Science in Sports and Exercise, 44, 180-189. PubMed doi:10.1249/ MSS.0b013e318228b60e

Nana, A., Slater, G.J., Hopkins, W.G., \& Burke, L.M. (2012b). Techniques for Undertaking DXA Whole Body Scans to Estimate Body Composition in Tall and/or Broad Subjects. International Journal of Sport Nutrition and Exercise Metabolism, 22, 313-322.

Nord, R.H., \& Payne, R.K. (1995). Body composition of dualenergy X-ray absorptiometry - a review of the technology. Asia Pacific Journal of Clinical Nutrition, 4, 167-171. PubMed

Oldroyd, B., Smith, A.H., \& Truscott, J.G. (2003). Crosscalibration of GE/Lunar pencil and fan-beam dual energy densitometers-bone mineral density and body composition studies. European Journal of Clinical Nutrition, 57, 977-987. PubMed doi:10.1038/sj.ejcn.1601633

Oliver, J. M., Lambert, B. S., Martin, S. E., Green, J. S., \& Crouse, S. F. (2012). Predicting football players' dualenergy x-ray absorptiometry body composition using standard anthropometric measures. Journal of Athletic Training, 47, 257-263.

Orchard, J.W., Read, J.W., \& Anderson, I.J. (2005). The use of diagnostic imaging in sports medicine. The Medical Journal of Australia, 183, 482-486. PubMed

Pietrobelli, A., Formica, C., Wang, Z., \& Heymsfield, S.B. (1996). Dual-energy X-ray absorptiometry body composition model: review of physical concepts. The American Journal of Physiology, 271, E941-E951. PubMed
Pietrobelli, A., Wang, Z., Formica, C., \& Heymsfield, S.B. (1998). Dual-energy X-ray absorptiometry: fat estimation errors due to variation in soft tissue hydration. The American Journal of Physiology, 274, E808-E816. PubMed

Plank, L.D. (2005). Dual-energy X-ray absorptiometry and body composition. Current Opinion in Clinical Nutrition and Metabolic Care, 8, 305-309. PubMed doi:10.1097/01. mco.0000165010.31826.3d

Prior, B.M., Cureton, K.J., Modlesky, C.M., Evans, E.M., Sloniger, M.A., Saunders, M., . ... (1997). In vivo validation of whole body composition estimates from dual-energy X-ray absorptiometry. Journal of Applied Physiology (Bethesda, Md.), 83, 623-630. PubMed

Pritchard, J.E., Nowson, C.A., Strauss, B.J., Carlson, J.S., Kaymakci, B., \& Wark, J.D. (1993). Evaluation of dual energy X-ray absorptiometry as a method of measurement of body fat. European Journal of Clinical Nutrition, 47, 216-228. PubMed

Quiterio, A. L., Silva, A. M., Minderico, C. S., Carnero, E. A., Fields, D. A., \& Sardinha, L. B. (2009). Total body water measurements in adolescent athletes: a comparison of six field methods with deuterium dilution. The Journal of Strength \& Conditioning Research, 23, 1225-1237.

Rothney, M.P., Brychta, R.J., Schaefer, E.V., Chen, K.Y., \& Skarulis, M.C. (2009). Body composition measured by dual-energy X-ray absorptiometry half-body scans in obese adults. Obesity (Silver Spring, Md.), 17, 1281-1286. PubMed

Rowell, L.B. (2004). Ideas about control of skeletal and cardiac muscle blood flow (1876-2003): cycles of revision and new vision. Journal of Applied Physiology (Bethesda, Md.), 97, 384-392. PubMed

Sanchis-Moysi, J., Dorado, C., Olmedillas, H., SerranoSanchez, J. A., \& Calbet, J. A. (2010). Bone and lean mass inter-arm asymmetries in young male tennis players depend on training frequency. European Journal of Applied Physiology, 110, 83-90.

Santos, D.A., Gobbo, L.A., Matias, C.N., Petroski, E.L., Goncalves, E.M., Cyrino, E.S., . . .. (2012). Body composition in taller individuals using DXA: A validation study for athletic and non-athletic populations. Journal of Sports Sciences, 31, 405-413. PubMed

Santos, D.A., Silva, A.M., Matias, C.N., Fields, D.A., Heymsfield, S.B., \& Sardinha, L.B. (2010). Accuracy of DXA in estimating body composition changes in elite athletes using a four compartment model as the reference method. Nutrition \& Metabolism, 7, 22. PubMed doi:10.1186/17437075-7-22

Sawka, M.N., Burke, L.M., Eichner, E.R., Maughan, R.J., Montain, S.J., \& Stachenfeld, N.S. (2007). American College of Sports Medicine position stand. Exercise and fluid replacement. Medicine and Science in Sports and Exercise, 39, 377-390. PubMed doi:10.1249/01. mss.0000272779.34140.3b

Silva, A.M., Baptista, F., Minderico, C.S., Rodrigues, A.R., Pietrobelli, A., Teixeira, P.J., . . .. (2004). Calibration models to measure body composition in taller subjects using DXA. International Journal of Body Composition Research, 2, 165-173. 
Silva, A. M., Fields, D. A., Heymsfield, S. B., \& Sardinha, L. B. (2010). Body composition and power changes in elite judo athletes. International Journal of Sports Medicine, 31, 737-741.

Silva, A.M., Heymsfield, S.B., \& Sardinha, L.B. (2013). Assessing body composition in taller or broader individuals using dual-energy X-ray absorptiometry: a systematic review. European Journal of Clinical Nutrition, 67, 1012-1021. PubMed doi:10.1038/ejen.2013.148

Silva, A.M., Minderico, C.S., Teixeira, P.J., Pietrobelli, A., \& Sardinha, L.B. (2006). Body fat measurement in adolescent athletes: multicompartment molecular model comparison. European Journal of Clinical Nutrition, 60, 955-964. PubMed doi:10.1038/sj.ejen.1602405

Smathers, A.M., Bemben, M.G., \& Bemben, D.A. (2009). Bone density comparisons in male competitive road cyclists and untrained controls. Medicine and Science in Sports and Exercise, 41, 290-296. PubMed doi:10.1249/ MSS.0b013e318185493e

Soriano, J.M., Ioannidou, E., Wang, J., Thornton, J.C., Horlick, M.N., Gallagher, D., . ... (2004). Pencil-beam vs fan-beam dual-energy X-ray absorptiometry comparisons across four systems: body composition and bone mineral. Journal of Clinical Densitometry, 7, 281-289. PubMed doi:10.1385/ JCD:7:3:281

Stewart, A. D., \& Hannan, J. (2000). Sub-regional tissue morphometry in male athletes and controls using dual X-Ray absorptiometry (DXA). International Journal of Sport Nutrition and Exercise Metabolism, 10, 157-169.

Stoggl, T., Enqvist, J., Muller, E., \& Holmberg, H.-C. (2010). Relationships between body composition, body dimensions, and peak speed in cross-country sprint skiing. Journal of Sports Sciences, 28, 161 - 169.

Sutton, L., Scott, M., Wallace, J., \& Reilly, T. (2009a). Body composition of English Premier League soccer players: influence of playing position, international status, and ethnicity. Journal of Sports Sciences, 27, 1019-1026. PubMed doi:10.1080/02640410903030305

Sutton, L., Wallace, J., Goosey-Tolfrey, V., Scott, M., \& Reilly, T. (2009b). Body composition of female wheelchair athletes. International Journal of Sports Medicine, 30, 259-265. PubMed doi:10.1055/s-0028-1105941

Svantesson, U., Zander, M., Klingberg, S., \& Slinde, F. (2008). Body composition in male elite athletes, comparison of bioelectrical impedance spectroscopy with dual energy X-ray absorptiometry. Journal of Negative Results in BioMedicine, 7, 1

Taguchi, M., Ishikawa-Takata, K., Tatsuta, W., Katsuragi, C., Usui, C., Sakamoto, S., et al. (2011). Resting energy expenditure can be assessed by fat-free mass in female athletes regardless of body size. Journal of Nutritional Science and Vitaminology (Tokyo), 57, 22-29.

Taylor, A., Konrad, P.T., Norman, M.E., \& Harcke, H.T. (1997). Total body bone mineral density in young children: influ- ence of head bone mineral density. Journal of Bone and Mineral Research, 12, 652-655. PubMed doi:10.1359/ jbmr.1997.12.4.652

Thomsen, T.K., Jensen, V.J., \& Henriksen, M.G. (1998). In vivo measurement of human body composition by dual-energy X-ray absorptiometry (DXA). European Journal of Surgery, 164, 133-137. PubMed doi:10.1080/110241598750004797

Toombs, R. J., Ducher, G., Shepherd, J. A., \& De Souza, M. J. (2011). The impact of recent technological advances on the trueness and precision of dxa to assess body composition. Obesity (Silver Spring).

Tothill, P., Hannan, W.J., \& Wilkinson, S. (2001). Comparisons between a pencil beam and two fan beam dual energy X-ray absorptiometers used for measuring total body bone and soft tissue. The British Journal of Radiology, 74, 166-176. PubMed doi:10.1259/bjr.74.878.740166

Van Loan, M.D., Keim, N.L., Berg, K., \& Mayclin, P.L. (1995). Evaluation of body composition by dual energy $\mathrm{x}$-ray absorptiometry and two different software packages. Medicine and Science in Sports and Exercise, 27, 587-591. PubMed doi:10.1249/00005768-199504000-00018

van Marken Lichtenbelt, W. D., Hartgens, F., Vollaard, N. B., Ebbing, S., \& Kuipers, H. (2004). Body composition changes in bodybuilders: a method comparison. Medicine \& Science in Sports \& Exercise, 36, 490-497.

Vilaca, K.H., Ferriolli, E., Lima, N.K., Paula, F.J., \& Moriguti, J.C. (2009). Effect of fluid and food intake on the body composition evaluation of elderly persons. The Journal of Nutrition, Health \& Aging, 13, 183-186. PubMed doi:10.1007/s12603-009-0055-4

Wang, Z.M., Deurenberg, P., Guo, S.S., Pietrobelli, A., Wang, J., Pierson, R.N., Jr., . ... (1998). Six-compartment body composition model: inter-method comparisons of total body fat measurement. International Journal of Obesity and Related Metabolic Disorders, 22, 329-337. PubMed doi:10.1038/sj.ijo.0800590

Warrington, G., Dolan, E., McGoldrick, A., McEvoy, J., Macmanus, C., Griffin, M., .... (2009). Chronic weight control impacts on physiological function and bone health in elite jockeys. Journal of Sports Sciences, 27, 543-550. PubMed doi:10.1080/02640410802702863

Withers, R.T., LaForgia, J., Pillans, R.K., Shipp, N.J., Chatterton, B.E., Schultz, C.G., .... (1998). Comparisons of two-, three-, and four-compartment models of body composition analysis in men and women. Journal of Applied Physiology (Bethesda, Md.), 85, 238-245. PubMed

Wittich, A., Oliveri, M.B., Rotemberg, E., \& Mautalen, C. (2001). Body composition of professional football (soccer) players determined by dual X-ray absorptiometry. Journal of Clinical Densitometry, 4, 51-55. PubMed doi:10.1385/ JCD:4:1:51 